\title{
Semantic Constraints on Case Assignment in Secondary Adjectival Predicates in Russian
}

\author{
Roland Hinterhölzl \\ Humboldt-Universität zu Berlin \\ roland.hinterhoelzl@rz.hu-berlin.de
}

\begin{abstract}
Adjectival secondary predicates can enter into two Case frames in Russian, the agreeing form and the Instrumental. The paper argues that these Case frames go together with two syntactic positions in the clause which are correlated with two different interpretations, the true depictive and the temporally restricted reading, respectively. The availability of the two readings depends on the boundedness of the secondary predicate. Only bounded predicates can enter into both Case frames and only partially non-bounded predicates can appear in the Instrumental. The paper therefore argues that the pertinent two-way SL/IL-contrast is to be replaced by a three-way distinction in terms of boundedness. The paper outlines the syntax and semantics of the true depictive and the temporally restricted interpretation and discusses how adjectival secondary predicates whose salient properties involve a cotemporary interpretation with the matrix predicate and a control relation of an individual argument, differ from temporal adjuncts as well as from non-finite clauses.
\end{abstract}

\section{$1 \quad$ Introduction}

In recent years, work on the much discussed Stage-level/Individual-level contrast has accumulated which argues convincingly that the pertinent distinction should not be handled in terms of a difference in the argument structure of the respective predicates (cf. Higginbotham \& Ramchand 1996, Jäger 1999). Nevertheless, the distinction is real and is relevant in one way or other in various environments. One such environment is the depictive use of adjectival secondary predicates. Already Rapoport (1991) noted that only SL-predicates can be depictives, as is illustrated in (1).

(1) a. Ronnie bought the dog sick

b. $\quad$ Ronnie bought the dog intelligent

In this paper, I argue that the distribution and interpretation of adjectival secondary predicates in Russian implies that, at least in the realm of adjectival predicates, instead of a two way distinction a three way distinction is called for, namely one between bounded, partially nonbounded and unbounded predicates.

\subsection{Case (Non-) Agreement}

In Russian, adjectival predicates agree with the NP they are predicated of in gender and number. Depending on their own meaning and on the meaning of the sentence they are contained in, they can also agree with the case of their antecedent NP, or appear in a distinct non-agreeing case, namely the Instrumental, as is illustrated in (2) ${ }^{!}$.

\footnotetext{
*I thank Natalia Gagarina and Anatoli Strigin for discussion of the data. A special thanks goes to Ljudmila Geist for extensive discussion and help with the data.

1 There are two exceptions to this generalization: odin (alone) and sam (self) always agree with their
} 
(2)
a. Ivan rabotajet golyj
John works naked-NOM
b. Ivan rabotajet golym
John works naked-INS

In this paper, I will show that only bounded adjectival predicates can appear in either form, with the agreeing form (in short NOM) being the unmarked form and the Instrumental occurring when additional conditions obtain, whereas non-bounded adjectival predicates can only appear in the Instrumental form. I will also show that the interpretation that these predicates receive systematically correlates with their syntactic position in the clause and the Case they are licensed with, as is summarized in (5).

\section{2 $\quad 1.2$ Types of Modification Relations}

Adjectival predicates can in principle enter into three types of modification relations, which I call the circumstantial reading, the pure depictive and the temporally restricted reading. In the circumstantial use, which is illustrated in (3), the secondary predicate describes the circumstances in which the assertion formed by the remainder of the clause holds. I propose that the adjective in the circumstantial reading is interpreted as forming the restriction of an unselective operator, whose nuclear scope is then provided by the rest of the clause, as is indicated in the translations in (3).
a. Golodnyj, on vernulsja domoj
Hungry-NOM he returned home
"When he was hungry, he returned home"
b. Sladkij etot caj nevkusnyj
Sweet this tea not-good
"If it is sweet, this tea is not good"
c. On i spjacij ne mog zabyt' etogo
He even sleeping not could forget this
"Even when he was sleeping he could not forget this"

The depictive reading and the temporally restricted reading are illustrated in (4a) and (4b), respectively. In (4a), the adjective describes the subject at the time it is engaged in the event expressed by the main verb. I propose that in the depictive use, the adjective expresses an independent event and that the clause is interpreted as a (logical) conjunction of two (independent) assertions.
a. On ženilsja na nej pjanyj
He married her drunk-NOM
"He married her (at time $t$ ) and he was drunk (at t)"
b. On ženilsja na nej molodym
He married her young-INS
"When he married her, he was young" 
In (4b), where it appears in the Instrumental, the adjective receives a rather different interpretation from the one in (4a). Here the adjective, in contrast to the circumstantial reading, forms the nuclear scope of an unselective (temporal) operator, whose restriction is provided by the remainder of the clause. In the remainder of the paper, I will only be concerned with the distinction between the depictive interpretation and the temporally restricted interpretation of adjectival predicates.

\begin{tabular}{|l|l|l|l|}
\hline reading & circumstantial & pure depictive & temporally restricted \\
\hline Case & NOM & NOM & INS \\
\hline Interpretation & C-domain & I-domain & V-domain \\
\hline
\end{tabular}

The paper is organized in the following way. In Section 2, I will discuss the differences in interpretation and distribution between the long form and the short form of the adjective. In Section 3, I will define the notion of a bounded predicate and discuss the behavior of bounded and non-bounded predicates with respect to the Case forms they can be realized with. In Section 4, I discuss the factors that determine the choice between agreeing form and Instrumental with bounded predicates. In Section 5, I discuss the different semantic properties of the true depictive and the temporally restricted reading and provide an account that relates these differences to differences in the syntactic licensing of these readings.

\section{Long Form/Short Form of the Adjective}

In this section, I will show that the secondary predicates in (2) -(4) above are truly APs and rule out the possibility of analyzing them as "hidden" NPs. It is necessary to make this argument for the following reason.

Modern Russian has two types of adjectives, the so-called long form (lf) and the socalled short form (sf). The long form has additional morphology and appears in attributive position, where the short form is impossible, as is shown in (6).

$$
\begin{aligned}
& \text { a. umnaja devuska } \\
& \text { smart-If girl } \\
& \text { b. * umna devuska } \\
& \text { smart-sf girl }
\end{aligned}
$$

However, as is shown in (7) both forms are possible in predicative position. Babby (1973, 1987, 1999) and Bailyn (1994) provide convincing arguments that the long form in predicative position is actually contained in an NP with a null nominal head, as is illustrated in (8). Bailyn (1994) shows that (7a) and (7b) differ slightly in their meaning as well. Whereas (7a) means the girl is smart in absolute terms, (7b) asserts that the girl is smart compared to other members of her class, i.e., she is smart for a girl or a woman. Bailyn (1994) argues that this semantic difference can be nicely coupled with the presence of an empty nominal in $(7 \mathrm{~b})$, which provides the reference class with respect to which the predication expressed by the adjective is made.

$$
\begin{aligned}
& \text { a. Devuska umna } \\
& \text { girl smart-sf 'the girl is smart' }
\end{aligned}
$$




\section{b. Devuska umnaja \\ girl smart-lf}

\section{Devuska [NP [AP umnaja] N ]}

As (9) shows only the long form is possible, when the adjective is used as a secondary predicate. This is surprising given the facts in (7) and the question arises whether the secondary predicate in sentences like (9) really is an AP or had better be analyzed as an empty headed NP containing an adjective as modifier. In this way, the contrast in (9) could be related to the constrast in (6). In other words, the question arises whether (9) really means something like 'he came home as a hungry person'?

\section{On vernulsja domoj golodnyj/*goloden}

He returned home hungry-NOM/hungry-sf

The answer is no and the argument is fairly simple. Note that an NP in the very same position as the adjective hungry in (9) can only appear in the Instrumental, never in the argeeing form, as is shown in (10). If golodnyj in (9) really were an NP then is it unclear why it can be spelled out with an agreeing Case, namely Nominative, which is the preferred option in (9).

On vernulsja s vojny oficerom/ *oficer

He returned from the war an-officer-INS $/ *$ NOM

Thus it follows that the secondary predicate in structures like (9) is an AP. On the other hand, the possibility remains that at least adjectival secondary predicates in the Instrumental are hidden NPs. Though a split along these lines is a highly unlikely state of affairs, we would like to rule it out if possible. This possibility can be ruled out with the help of certain nouns which can only appear with the short form of the adjective in predicative position. These are nouns which are not members of a class by virtue of being unique. One such noun is 'kosmos' which does not admit any long form in predicative position, as is illustrated in (11a).

(11) a. Kosmos neobitaem/??neobitaemyj/*neobitaemym the universe uninhabited

b. Kosmos mne nravitsja nebitaemym/*neobitaem the universe me pleases uninhabited

As (11b) shows the same adjective applied to the noun Kosmos as a secondary predicate can appear in the Instrumental while the short form is ungrammatical. Again, if the adjective in the Instrumental were part of an NP, then it remains unclear why the long form should be possible here. Thus we can safely conclude that adjectival predicates both in the agreeing form and in the Instrumental are true APs.

The question remains, though, why adjectival secondary predicates, contrary to primary adjectival predicates, cannot appear in the short form. In order to explain the distribution of the short and the long form in Russian, Bailyn (1994) proposes that the long form morphology heads the functional category ModP (for Modifier Phrase). What unites the attributive use of the adjective and the use as secondary predicate is the fact, that in both cases the adjective modifies another category, an NP and a VP respectively. 
This is certainly an interesting proposal, though it is unclear whether the semantic relation of modification needs to be expressed by a syntactic head rather than being merely represented as syntactic adjunction. Thus, I will leave this question open for future research.

\section{Semantic Constraints on Case assignment}

In this section, I will explicate one factor that determines which of the two forms, the agreeing form or the Instrumental, is appropriate in a given context. It is the semantic type of the adjective itself which restricts the availability of the two forms in the following way. Only adjectives that denote a temporary state can appear in the agreeing form. Being drunk is a paradigm case of a temporary state. As (12a) and (12b) show, an adjective like drunk can appear in both forms, whereas an adjective like young, which is generally thought of as denoting a property, is only good in the Instrumental.
a. On ženilsja na nej pjanyj/pjanym
He married her drunk-NOM/drunk-INS
b. On ženilsja na nej molodym/??molodoj
He married her young-INS/young-NOM

This immediately raises the question of how we can define a temporary state? Afterall, being young is not a permanent property like being intelligent or having blue eyes. It is less temporary than being drunk, for sure, but it denotes a property that is being lost in the second or third decade in one's life. Also, the ripeness of a fruit is a relatively short temporary state (it lasts a couple of days), whereas the sickness of a person can last for several weeks. Nevertheless, ripe can only appear in the Instrumental, whereas sick can be used in its agreeing form (cf. (13)). I will define a temporary state as given in (14).
a. On sobral slivy spelymi/* spelye He plucked the plums ripe-INS/ripe-AKK
b. Ona vstretila jego bol'nogo/bol'nym She met him sick-AKK/sick-INS

(14) An adjectival predicate $\mathrm{P}$ denotes a temporary state (i.e., is bounded), if $\mathrm{P}$ is both preceded and followed by a state the can be characterized by not $P$ in the language system

Note that it is crucial in (14) to refer to the language system. While it is true that when a fruit is rotten it is not the case that it is ripe, it is not strictly speaking non-ripe. That is to say, the past ripe state of a fruit is not conceptualized as non-ripe. A good test for how adjectives are categorized with respect to this property are the so-called phase quantifiers and their negations (cf. Löbner (1989). Noch nicht $P$ (not yet $P$ ) requires that $\mathrm{P}$ is preceded by a state characterizable as non-P. Nicht mehr $P$ (not $\mathrm{P}$ anymore) requires that $\mathrm{P}$ is followed by a state characterizable as non-P. The Russian equivalences are ne...jesce and ne...uze.

\footnotetext{
a. Kogda ja sobral slivy, oni ješčel *uze byli ne spelyje

When I plugged the plum, it yet/anymore not was ripe

"... it was not yet ripe/... it was not ripe anymore"
} 
b. Kogda ja vstretil Ivana, on ješče/uze byl ne bolnym/pjanym/serditym When I met Ivan, he yet/anymore not was sick/drunk/angry

c. Kogda ja vstretil Ivana, on *ješče/uze ne byl molod/naiven/nevinen When I met Ivan, he yet/ anymore not was young/naive/innocent

d. Kogda ja vstretil Ivana, on ješče/*uze ne byl starym/xoroso obrazovanym When I met Ivan, he yet/ anymore not was old/well-educated

e. Kogda ja vstretil Ivana, on*ješče/*uze ne byl umnym/glupym When I met Ivan, he yet/ anymore not was intelligent/stupid

As (15b) shows, typical temporary predicates like sick, drunk and angry meet both criteria. I will call these predicates bounded, i.e., they have an upper and a lower bound. Predicates like ripe and young only meet one of the tests. (15) also shows that typical cases of individual level predicates like intelligent and stupid meet none of the two tests. I will call the latter two types of predicates non-bounded.

According to the criterion in (14) raw and cooked are non-bounded, as is illustrated in (16ab). Thus, it is predicted that these predicates cannot appear in the agreeing form. This prediction is borne out. In (16c) only the Instrumental is possible.
a. Kogda on kupil mjaso, ono *ješče/uze bylo ne syroje
When he bought the meat, it yet/anymore not was raw
b. Kogda on kupil mjaso, ono ješče/*uze bylo ne varjonoje
When he bought the meat, it yet/anymore not was cooked
c. On sjel mjaso syrym a frukty varjonymi
$\mathrm{He}$ ate the meat raw but the fruits cooked

The semantic type of the adjective also restricts the availability of the Instrumental form. If an adjective is non-bounded (intelligent, stupid, well-educated, literate, innocent, naive), only those that denote a property that can be either acquired (well-educated, literate) or lost (innocent, naive) that is, those that meet one or the other of the above tests, can appear in the Instrumental form, as is illustrated in (17).

a. On vysel iz universiteta xoroso obrasovannym/* umnym He came out-of the University well-educated/ intelligent

b. On ženilsja na ne absolutno naivnym/* glupym He married her completely naive/ stupid

I will call the predicates that admit the Instrumental partially non-bounded and those that don't unbounded predicates. We thus arrive at the following correlation between the semantic type of a predicate and the Case forms it admits in Russian (where NOM is short for agreeing Case):

\section{bounded} NOM/INS partially non-bounded *NOM/INS unbounded

$* \mathrm{NOM} / * \mathrm{INS}$ 
I will conclude this section with an example that illustrates the correlation between semantic type and syntactic Case form by the way of a minimal pair. In (19a), the adjective 'big' in its agreeing form means 'big compared to other individuals of the class of elephants'. The adjective in the Instrumental means 'grown to full size', i.e., big compared to other stages of an elephant. If the adjective is used as a secondary predicate only the Instrumental is possible (19b). This is entirely expected since it is the Instrumental in (19a) that expresses a property that can be acquired, whereas the agreeing form is used to specify the unbounded reading in (19a).
a. Etot slon byl bolsoj/bolsim
This elephant was big-NOM/INS

b. Ivan vstretil etogo slona *bolsogo/bolsim

Ivan encountered this elephant big-AKK/INS

\section{The Choice of the Case form with Bounded Predicates}

When the secondary adjectival predicate is a bounded predicate, the choice of the correct Case form in a given context seems to depend on a number of factors. I have to make clear at the outset that in this area I found a lot of speaker variation. The distinctions seem to be rather subtle and in many cases are just a matter of preferences rather than a matter of grammaticality.

In the following, I will thus report only the factors which proved to be the most robust, that is, I will discuss the factors that were considered relevant by the majority of the native speakers asked and will then compare my findings with those reported in the literature, especially with Nichols (1981) and Timberlake (1986). In general, the agreeing Case represents the unmarked form with the Instrumental showing up when additional conditions obtain.

If the adjective is a bounded predicate like naked, the choice between the agreeing and the Instrumental form depends on the temporal reference of the sentence, as is illustrated in (20). If the sentence has a specific time reference, the agreeing form is obligatory (20a). If the sentence has a generic or habitual reading, the Instrumental is preferred (20b). I will call this interpretation the temporally restricted reading to distinguish it from the pure depictive reading in (20a).
a. Ivan rabotajet golyj
John works naked-NOM
"John works and is naked now"
b. Ivan rabotajet golym
John works naked-INS
"John usually works/has the habit of working naked"

For some speakers the adjective in (20b) has a kind of manner interpretation. Whereas the process of John's working and the state of his being naked seem to coincide accidentally in (20a), John's nakedness appears to be volitional and controlled by the subject. In other words, (20b) may also express that being naked is the way or manner in which John (usually) works. We may assume that the manner reading is a derivative of the habitual reading - an inference which some speakers seem to make but is seemingly not necessary for all speakers. 
The manner interpretation of (20b) goes very well with the following observation. Adjectives describing psychological states (sad, angry, happy) cannot appear in the Instrumental. First, note that psychological adjectives cannot describe the manner in which an event is performed: to purposefully perform some act in a certain manner requires control over that manner. Psychological adjectives express inner states that are not controllable and unvolitional. Hence, they can only be interpreted as true depictives. This is illustrated in (21a). There is one systematic exception to the generalization that psychological adjectives cannot appear in the Instrumental. As shown in $(2 \mathrm{lb})$, sentences that explicitly contrast the states expressed by adjectival predicates permit the Instrumental.
a. Ivan rabotajet grustny/*grustnym John works sad-NOM/sad-INS
b. Segodnja on usel veselym, a prisel grustnym
Today he left cheerful-INS and returned sad-INS

The interpretational differences in (20) and the difference in grammaticality in (21a) seem to suggest that the adjective in the Instrumental is interpreted in a lower position, that is, within the scope of the abstract causative verb $v$ (cf. Hale \& Keyser 1993, Chomsky 1995) than the adjective in the agreeing form. This reasoning is supported by the fact that, if the two forms are combined in one clause, which yields a marked sentence, only the order in which the agreeing form occupies the higher position is grammatical, as is shown in (22).

\section{a. Ivan rabotajet golym serdityj \\ John works naked-INS angry-NOM \\ b. $\quad$ Ivan rabotajet serdityj golym \\ John works angry-NOM naked-INS}

Let us now have a brief look at the literature on the subject and see how our findings square with the observations found there. The two most comprehensive investigations of the issue at hand are Nichols (1981) and Timberlake (1986). Nichols describes a dozen or so factors comprising stylistic, morphological, syntactic, semantic as well as pragmatic ones, that influence the choice of case. This study, thus, reflects rather directly my own observation that speakers seem to have difficulties to agree on a relatively small set of factors.

Timberlake's (1986) study is of more explanatory value. In a statistical survey of texts that he augmented with the judgments of 8 native speakers, he extracts two factors as decisive. He also notes that the agreeing Case is the unmarked form with the Instrumental appearing when additional conditions are observed. He distinguishes between the temporal and the modal use of the Instrumental. According to Timberlake, "the temporal instrumental signals that the event denoted by the adjective occurs in temporal sequence in relation to other events in the text"(p.142).

The temporal use of the Instrumental is illustrated in (23) and (24). In (23), the adjective sets the stage for the subsequent events expressed in the remainder in the clause, whereas in (24), the event expressed by the adjective is temporally located with respect to the other events in the narrative.

Here's what happened once: I came home from the Academy hungry-NOM, stoked up the cookstove, and started to cook some kasha from the remains of the groats 
Stepan, having lolled around the hospital for a month, returned home healthy-INS

The modal use of the Instrumental is illustrated in (25). According to Timberlake, "the modal instrumental signals that the state not only holds at the narrated occasion, but holds contrary to expectations derived from general principles" (p. 146). What these general principles are in the concrete case is left undefined by Timberlake. In (25), it is the general expectation that the grass wilts in the fall before it is covered with snow in early winter.

\section{The following spring the grass grew thick and lush, and went under the snow green-INS}

In Nichol's study change of state is an important factor for choosing the Instrumental over the agreeing form. Also Kennedy \& Filip (2000) argue that the Instrumental conveys an added meaning of 'change of stage'. However, some of Timberlake's examples clearly show that 'change of state' cannot be a decisive factor. In (25), the grass went unchanged, namely still green, under the snow. And in (26), the subjects talked about remain unnoticed and the jug remains empty. Nevertheless, the Instrumental is obligatory in these sentences, as is confirmed by the unequivocal native speaker judgments in (26a): of eight speakers consulted, all eight said that they would use the Instrumental in the given sentence.

(26) a. They passed through the front lines of the enemy unnoticed-INS

(8 INS, 0 NOM)

b. Twice on that day he descended to the bottom of the jug and twice he came up empty-INS

In our account, it is quite clear why the Instrumental is obligatory in (26a). The adjective unnoticed is not a bounded predicate. It only has an upper boundary. The same holds for (27). The person in question was already well-educated before he came to us. Again, there is no change of state implied in (27). Nevertheless, the adjective has to appear in the Instrumental Case, since the adjective does not denote a bounded predicate.

\section{On prisel $k$ nam xoroso obrazovannym \\ He came to us well-educated-INS}

What is really necessary for an adjective to enter into a secondary predication relation is the fact that the adjective denotes a state that has the potential for change. In my account, a predicate has a potential for change if it has at least an upper or a lower bound.

To summarize, what Timberlake calls the temporal use of the Instrumental looks very much like what I called the temporally restricted interpretation of the Instrumental. And what Timberlake calls the modal use of the Instrumental might simply be a subcase of the contrastive interpretation of the Instrumental that I pointed out in connection with psychological predicates.

Thus, we may conclude that with bounded adjectival predicates the Nominative is used as a default and that the Instrumental is preferably used when either the state expressed by the adjective is contrasted with another state (modal use) or when this state is temporally restricted by or temporally ordered with respect to other events in the clause or the context (the temporal use). 


\section{$5 \quad$ The Syntax and Semantics of Depictives}

Contemplating the semantic contribution of depictive predicates, it seems that a depictive predicate describes its subject at the time it is engaged in another event. In other words, we may say that the main verb and the depictive adjective are predicated of the same stage of an individual. Though these two characterizations of the role of depictives sound almost synonymous, I will show below that they are not and that only the second characterization is correct.

In clauses with depictives, we are dealing with two independent events which are solely related by sharing a participant. That is to say that with depictives, contrary to temporal adjunct clauses, neither event directly specifies (the temporal location of) the other. In the following, I want to address two questions. A) How are depictives to be distinguished from verbal adjuncts, that is, other event-predicates, in a Davidsonian framework? B) Where and how do depictives attach to the clause?

Let us first discuss the question of how depictives can be distinguished from verbal adjuncts. A typical case of verbal modification is given in (28). In this situation, some adjunct $\mathrm{XP}$, for instance, a manner adverb, adjoins to the VP. The semantic interpretation of this syntactic operation is that the two event arguments are identified.

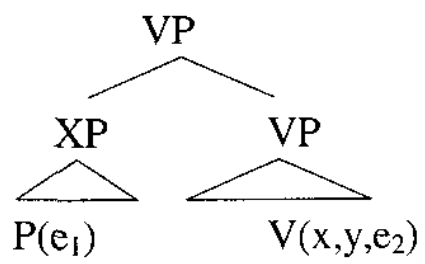

modification: $\mathrm{e}_{1}=\mathrm{e}_{2}$

This is of course not what we want in the case of a depictive secondary predicate as in 'John works naked (now)'. I assume that naked is a two place predicate comprising an event argument and an individual argument (naked $(\mathrm{x}, \mathrm{e})$ ). As I stated above clauses with depictives really involve two events. If anything is to be identified it is the external argument of the verb and the individual argument of the depictive predicate in the example above. There are basically two ways of achieving this.

The first option is to treat functional heads as argument selectors as is illustrated in (29). Aspectual heads would then select the event argument of the verb for further modification whereas Agreement heads would select the respective individual argument for additional specification. To yield the correct interpretation of depictives, only one additional condition has to be ensured, namely that the depictive event $e_{2}$ properly contains the matrix event $\mathrm{e}_{1}$. In depictive relations the event expressed by the depictive adjective and the event expressed by the main verb overlap, but there is no implication that the depictive event incepted with the matrix event nor that it ends when the matric event ceases. Thus, the correct characterization between matrix event and depictive event seems to be that $\mathrm{e}_{1} \delta \mathrm{e}_{2}$. 
(29)

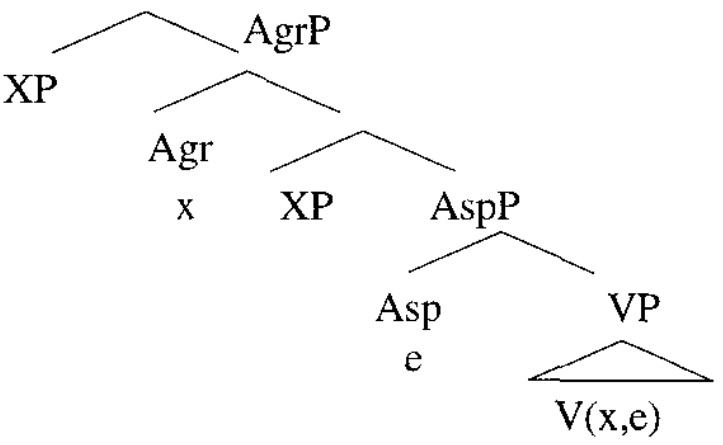

This account has several advantages. First, it would provide us with a unified theory of the syntax and semantics of adjuncts. Secondly, it would give semantic justification to Agreement Phrases (cf. Chomsky 1995, who dismisses AgrPs for lack of semantic impact). Thirdly, if one desires so, one could get rid of PRO which is needed to achieve what otherwise is done with argument identification.

However, there are also problems with this approach. First, English data (VPpreposing, though-movement, Wh-clefting) indicate that both subject and object oriented depictives are part of the VP (cf. Andrews 1982), as is illustrated in (30). Secondly, I will argue below that adjectives in the Instrumental are licensed in the VP.

(30) a. Noa said that she would eat dinner nude, and eat dinner nude she did

a.' $\quad$ Noa said that she would eat the meat raw, and eat the meat raw she did

b. Eat dinner nude/the meat raw though Noa did, nobody thought she was crazy

c. What Noa did was eat dinner nude/the meat raw

The second option assumes that depictives are base-generated in the VP and may adjoin to Agr-projections in the course of the derivation In this approach, we assume that the effect of argument identification is achieved via a control relation of PRO within the depictive predicate.

I do not take any stand here on whether the Larsonian approach as illustrated in (31a) or the standard approach in terms of right-adjunction as illustrated in (31b) should be taken. I only want to mention that in the Larsonian approach it is more difficult to identify the controller of PRO structurally, whereas in the standard approach the controller can be simply identified as the closest m-commanding DP.

a.

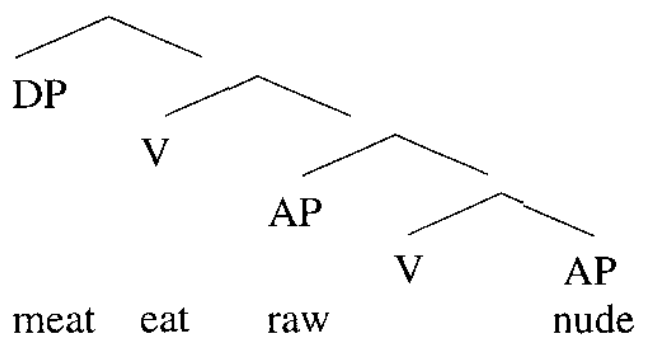

b.

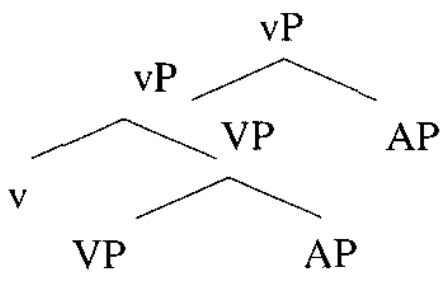

eat the meat raw nude

I assume that depictives in the Instrumental are base-generated and licensed in the VP and can thus remain there. Following Bailyn and Citko (1999), I assume that the Instrumental is an inherent Case that is assigned by Pred ${ }^{0}$ just in case Pred ${ }^{0}$ is not itself assigned Case (cf. (32)). This Case is then checked by movement of AgrP into [Spec,PredP]. The event 
argument of the depictive in the Instrumental is then bound by a temporal operator the restriction of which is formed by the rest of the clause, as is illustrated in (34) below.

$$
\left[\text { PredP } \operatorname{Pr}^{0} \quad[\text { AgrP PRO [Agr AP]]] }\right.
$$

Furthermore, I assume that depictives in the agreeing case are base-generated in the VP as well, but are licensed by adjoining to the respective AgrP where they receive the true depictive interpretation (neither event locates the other).

Let us again look at the semantics of depiction with respect to predicates which only have a lower boundary like ripe, well-educated and literate. We saw that these predicates cannot be interpreted as true depictives. They cannot appear in the agreeing form and are realized in the Instrumental, receiving the restrictive temporal interpretation. Given the semantics of depictives in which the depictive event properly contains the matrix event and given the fact that predicates with a lower boundary once they are acquired become permanent properties, it follows why these predicates pattern with unbounded predicates like intelligent in not admitting a true depictive interpretation: at the interval during which the matrix event holds predicates with only a lower boundary have already become timeless properties, as is illustrated in (33).

a. He left the University well.educated-INS

b.

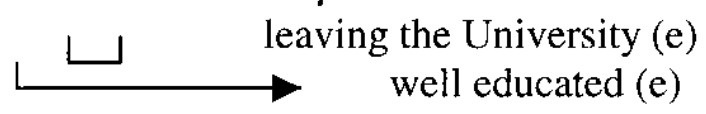

The question then arises why predicates with only a lower boundary can be rescued by being put in the Instrumental Case while unbounded predicates like ,intelligent " cannot, as is illustrated in (34a). As the contrast in (34bc) shows, this distinction can be reduced to a distinction that holds between the respective interpretations of (34a). I assume that (34c) is out for pragmatic reasons. It is simply infelicitous to temporally restrict an atemporal property like intelligent.
a. On vysel iz, universiteta xoroso obrasovannym/*umnym He came out-of the University well-educated/intelligent
b. When he left the university, he was well-educated
c.?? When he left the university, he was intelligent

Let us now look at the semantics of depiction with respect to predicates which only have an upper boundary like young, naive and raw, as is illustrated in (35). With the given semantics, namely that the depictive event properly contains the matrix event, we cannot explain why these predicates cannot be true depictives. At the interval during which the matrix event holds predicates with an upper boundary do not denote a timeless property and are in this respect clearly distinct from unbounded predicates. Note also that so far we have no explanation for why true depictives must be stage level predicates, that is, must be bounded predicates. 
a. On zenilsja na nej molodym

He married her young-INS

b.

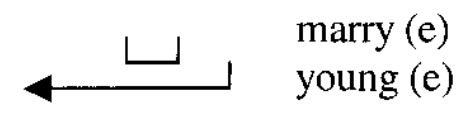

Below I will argue that this restriction follows from two assumptions. A) In adjectival predication, subject and predicate agree in boundedness. B) While temporal clauses relate intervals, depictives relate stages.

I think that Carlson (1977) was right in proposing the existence and relevance of stages, but not with respect to the assumption that stages are arguments of specific predicates. I like to propose to treat stages as interpretations of DPs, where a stage is defined as a pair of indices, an individual one and a temporal one such that $(i, t):=$ the stage of individual $i$ at time t. Furthermore, I will assume that a bounded individual is interpreted as a stage of that individual.

To illustrate that not only events but also individuals have a temporal dimension, let us look at an utterance like (36) in the context that Peter is dead now. Kripke, establishing the causal theory of names, convincingly argues that a name keeps on referring to the causally related bearer however that person or the world around him may change. In this theory, we may wonder what the name Peter refers to, now that Peter is dead. Depending on one's philosophical preferences it could be Peter's eternal soul or a bundle of bones in Peter's grave. In any event, and this is only half jokingly put, we do not want (36) uttered now to mean that Peter's eternal soul or his bones visited Mary a year ago. In an intensional semantic framework (36) would not render any difficulties. One would evaluate the expression Peter with respect to a past time and it would denote the set of properties that Peter had at this time and (36) would then state that among those be the property of visiting Mary. However, within a purely extensional framework like Davidson's this option is not available and it seems to me that to solve this problem one needs to be able to talk about temporal slices of an individual, that is, in the case at hand, of a past stage of Peters'.

\section{Peter visited Mary last year.}

That stages are not necessarily arguments of particular predicates may be illustrated in the following way. One may wonder whether a predicate like green is a stage-level or an individual level predicate. It seems that the answer to this question depends on the choice of the subject (37a). And (37b) is a case where both readings are available with the same subject. (37) can mean that the light has a green phase just now or that the light as physical object is (painted) green. In my view, the readings depend on what the DP die Ampel is meant to refer to, to an individual or to a stage of that individual.

a. Die Erbsen sind grün. Die Bananen sind (noch) grün Peas are green. Bananas are (still) green

b. Die Ampel ist grü.

The traffic-light is green

Given the assumptions made so far, how can we derive the restriction on stage-level predicates with depictives? I don't know whether there is a genuine semantic account of this restriction but a syntactic account could look like this. If depictive predicates do not contain a tense-head, as I have assumed in (32), then the proposition expressed by the depictive can 
only be temporally anchored, if the subject of the depictive is assigned (via control by its antecedent) an interpretation of a stage. In other words, the subject is assigned, instead of a single index of an individual, a pair of indices, an individual one and a temporal one. This is different from the control relation in infinitival clauses. As (38a) shows, in infinitival clauses two assertions can be made about two different stages of the same individual. This is possible since infinitival clauses contain an extra Tense-head which is subject to independent temporal control by the matrix verb. This is also different from temporal adjuncts which specify or restrict the temporal index of the matrix predicate. As (38b) illustrates, these expressions relate intervals.

\section{(38) a. Peter promised [ PRO to visit Mary tomorrow] \\ b. Yesterday/when Mary came in, Peter slept}

Coming back to depictive secondary predicates, since subject and predicate agree in boundedness as I have assumed above, it follows that only bounded predicates may appear in true depictives. With predicates in the Instrumental, the event argument is bound by a temporal operator. Thus they are not subject to temporal anchoring via Tense and only have to obey the weaker pragmatic condition of denoting temporally restrictable properties.

\section{References}

Andrews (1982): A note on the constituent structure of adverbials and auxiliaries. Linguistic Inquiry 13, 313-317

Babby, Leonard (1999): Adjectives in Russian: Primary vs. Secondary Predication. FASL, 1999.

Bailyn, John (1994): The Syntax and Semantics of Russian Long and Short Adjectives: An X'-Theoretic Account. FASL. Ann Arbor, Michigan Slavic Publications.

Baylin, John and Barbara Citko (1999): Case and Agreement in Slavic Predicates. FASL: The Seattle Meeting. Ann Arbor, Michigan Slavic Publications.

Carlson, Greg (1977): A unified analysis of the English bare plural. Linguistics and Philosophy 1, 413-457.

Filip, Hana and Chris Kennedy (2000): The Semantics of Case in Russian Secondary Predicates. Workshop on Predicative Constructions. ZAS, October 16-17, 2000.

Higginbotham, James and Gillian Ramchand (1996):The Stage-Level/Individual-Level Distinction and the Mapping Hypothesis. Manuscript, University of Oxford.

Jäger, Gerhard (1999): Stage levels, states and the semantics of the copula. In: ZAS Papers in Linguistics 14, 6594.

Kripke, Saul A. (1972): Naming and Necessity. Harvard University Press. Cambridge, Massachusetts.

Löbner, Sebastian (1989): German ,Schon-Erst-Noch: An integrated Analysis“. Linguistics and Philosophy 12: 167-212.

Nichols, Johanna (1981): Predicate Nominals: A Partial Surface Syntax of Russian. University of California Press. Volume 97.

Rapoport, Tova (1991): Adjunct Predicate Licensing and D-Structure. Syntax and Semantics 25. Academic Press, Inc.

Timberlake, Alan (1986): The Semantics of Case in Russian Predicate Complements. Russian Linguistics 10, 137-165. 